\title{
The information Resource as a Basis for Digital Reorganization of Career Guidance System and Prospective Recruitment of Personnel for Enterprises of the Mineral Resource Cluster
}

\author{
Tatjana Panina ${ }^{1, *}$, and Sergej Dochkin ${ }^{1}$ \\ ${ }^{1}$ T.F. Gorbachev Kuzbass State Technical University, 650000 Kemerovo, 28 Vesennya st., Russian \\ Federation
}

\begin{abstract}
The article presents proposals for the organization of targeted selection of personnel for their subsequent training for enterprises of the mineral resource cluster of the region. Special emphasis is placed on training future specialists who are potentially positioned to solve engineering problems and master mining technologies in the context of digital transformation of the economy. The relevance is confirmed by the processes of digitalization of the economy, active use of social networks and network services by young people, which requires changes in conceptual certainty and correction of the validity of professional selfdetermination and professional orientation. The main task is to develop technological mechanisms for the implementation of professional selfdetermination and professional orientation of young people in the conditions of digital modernization of the economy. A new model of complex professional orientation and professional self-determination of young people in the educational territorial ecosystem created on the basis of professional connections, acting on the basis of the results of data analysis obtained during the processing of digital user profiles, is proposed. Expected results are the following: the concept of expanding a multi-level intelligent IT platform for a geographically distributed model of professional orientation and professional self-determination of young people; principles of modeling psychological, physiological and cognitive features of a social network user (potential University applicants) based on their digital footprint for solving problems of individualization of the learning process; algorithm for working with the data obtained to form an individual trajectory of personal development. Such approaches will allow changing the idea of professional self-determination as a temporary process at a certain stage of personal development, prolonging activities for the formation and change of career for the entire professional activity of the individual, and ensure the reproduction of highly qualified personnel for the mining industry in the region.
\end{abstract}

\footnotetext{
*Corresponding author: idpo@kuzstu.ru
} 


\section{Introduction}

The problem of professional self-determination of young people is not new, and over time its solution becomes more relevant as the requirements for personnel for high-tech industries, including enterprises of the mineral resource cluster, particularly in the mining ones. In the context of digital changes in the economy, rapid development of technologies and transformation of society, questions of professional self-determination and professional orientation of young people are becoming increasingly important. We have to admit that career guidance based on traditional principles is unsystematic and episodic. Career guidance services and services offered by educational organizations and municipal institutions have not become a real means of forming the life path of students, a tool for designing personal professional careers [1,2]. At the same time, training in engineering (mining) specialties requires not only special training, but also certain personal data, individual abilities and interests of applicants - future students of the technical University, future personnel of the mining enterprises.

The research conducted at the Kuzbass State Technical University found that $35-36 \%$ of students could not remember the presence of career guidance in general education organizations, while the majority of them (77-88\%) noted the conduct of various career guidance and campaigning events conducted directly by the administration of the Kuzbass State Technical University [3]. In general, over the past two or three years, applicants have rated the University's information activities quite highly: $77 \%$ are satisfied with the format of open door meetings of the KuzSTU, $83 \%$ of applicants use the page of the KuzSTU in the social network "Vkontakte", $80 \%$ of them believe that campaigning to attract applicants to the KuzSTU is carried out at the proper level. It should be noted that the main factor in the final choice of the future profession is external influence: $26 \%$ - the University's website, 29\% - campaign and information events of the KuzSTU, 26\% - recommendations from teachers, relatives, and friends. On the other hand, the problem of personal readiness and internal predisposition of young people to the future profession, the ability of young people to study the relevant disciplines, master certain types of professional activity, and form their competence remains out of focus [12].Annual studies have shown that only 12$13 \%$ of applicants enter a technical university, as they have an interest in technical sciences, have the appropriate thinking and aptitude [17]. For others, the priority is other motives: a possible large income, promotion, diverse activities and the prestige of the profession.

As a result, universities are guided by the average indicator of readiness of applicants, which is formed from the results of the unified state exam and the personal portfolio of the applicant student. As a consequence, after the beginning of training, teachers are faced, especially in the first year, with a low creative potential and with the lack of training of first-year students to learn new material. At the same time, admission committees do not have effective tools for assessing the educational needs and readiness of applicants for the training process in an educational organization of professional education. As a result, approximately $33-36 \%$ of first-year students are disappointed with their choice by the end of the first semester, and another $27-28 \%$ of them begin to experience difficulties in mastering the material due to insufficient preparation or internal personal qualities [12].

In this regard, it is necessary to note the importance of transforming the regional system of professional orientation, which is based on the widespread introduction of modern digital technologies, the development of open information spaces, the use of network services and their potential.

In our opinion, three directions can be identified for the transformation of the system of professional self-determination and professional orientation of young people: the first, multi-sided theoretical and practical research of the basics and patterns of professional selfdetermination and professional orientation, related to the development of various 
organizational and pedagogical models; the second is the work on organizing the interaction of various structures and authorities, the economy, the labor market of the region and educational organizations; the third is the digitalization of the main processes for selecting a potential group for subsequent "point" work.

\section{Materials and Methods}

The problems of planning the professional future of young people are the subject of research by many scientists: the study of professional and personal self-determination (E. M. Borisova, E. A. Klimov, T. V. Kudryavtsev, N. N. Nikitina, N. S. Pryazhnikov, M. V. Retivykh, etc.), the study of professional formation of the individual (E. A. Klimov, A. K. Markova, E. S. Romanova, V. D. Shadrikov, etc.), the concept of personal formation as a subject of their professional activities (I. V. Samukina, A. R. Fonarev, etc.), the concept of professional formation in the context of career development (JH. Super), the concept of professionalism (A. K. Markov), the theory of professional development (E. Ginsberg, F. Parsons), etc. Issues of support and support of professional self-determination and career are the sphere of scientific interests of N. F. Rodichev, S. N. Chistyakova and others. Various aspects of personal, value, social, profile, professional self-determination are widely represented in the works of V. I. Blinov, E. I. Golovakha, N. E. Kasatkina, L. P. Krivenko, A. K. Oreshkin, A. E. Popovich, M. V. Retivykh, S. N. Chistyakova, T. I. Shalavina etc. Understanding the essence of professional self-determination contributed to the study of the dependence of the formation and development of individual characteristics on the inclusion of students in related activities (K. A. Abulkhanova-Slavskaya, B. G. Ananyev, A. G. Asmolov, V. A. Bodrov, L. S. Vygotsky, Yu. M. Zabrodin, S. V. Kalinina, E. A. Klimov, A. N. Leontiev, A.V. Mudrik, K. K. Platonov, S. D. Polyakov, L. M. Mitina, etc. $[13,17]$.

The research of A. M. Novikov, A. K. Oreshkina, V. P. Panasyuk, V. A. Polyakov, A. E. Popovich, I. P. Smirnov, E. V. Tkachenko, and A. R. Usmanov was aimed at the pedagogical problems associated with the development of non-professional professional education, the features of its reorientation in the new economic conditions. Of particular interest at present is the foreign experience of professional self-determination of students and career development of specialists. Certain aspects of pre-professional and professional training of students in the United States and Germany are covered in the works of A. R. Demchenko, M. V. Morozova, L. I. Melnikova, N. Mikhailova, D. Kipnis, N. S. Stepanov, M. V. Slavgorodskaya, E. E. Fedotova, A. G. Shirin.

This allowed us to sufficiently clarify the conceptual apparatus, generalize the theory, principles, methods, forms, define the tasks, structures of professional orientation and professional self-determination of students, and it can be summarized that this direction is actively developing at the present time. Problems of formation of professional selfdetermination of students were studied at all levels of education, and at many levels of interaction. Indeed, higher education institutions and educational organizations of secondary professional education are increasingly becoming subjects of the labor market, and this determines their desire to strengthen interaction with the external environment.

The concept of organizational and pedagogical support for professional selfdetermination of students in the conditions of continuous education, presented by $\mathrm{V}$. I. Blinov and I. S. Sergeev, defines the characteristics of post-industrial society, which include social and professional self-determination as the central mechanism of socioeconomic development of the country and the region [13]. Professional self-determination is a continuous process carried out in the form of gradual building of an individual set of general and professional competencies, based on his personal capabilities and needs. Because of this, it becomes relevant to help a person not in choosing a profession, but in 
finding resources for self-formation of their own educational and professional format, as well as learning how to use these resources. This approach was laid down in the region's multi-level set of models of pedagogical support, the main idea of which is to organize coordinated activities of subjects that ensure the functioning of the territorial multi-level system of pedagogical support for professional self-determination of students. The complex includes: a regional model of pedagogical support for professional self-determination of students; a municipal model of pedagogical support for professional self-determination of students; a pedagogical model of support for professional self-determination of students in an educational organization.

Currently, a special place is occupied by the question of technologization of the entire process of "entering the profession", respectively, the works that reveal the processes of professional orientation and professional self-determination at the technical (digital) level are of interest. In an environment where new mining professions appear every year, when the entire learning process is being actively transformed through aggressive push-through of network services, on-line training, automated management systems and training, social networks and network interaction for the process of professional orientation and professional self-determination require slightly different approaches and models. Now the so-called "digital footprints", "digital user profiles", and "digital identification" are being actively used in business. They are gradually being applied in pedagogy, psychology, and sociology. The works of H. Schwartz, M. Kosinski, L. Goldberg, A. Feschenko, A. Fagerstrom, V. Goiko, D. Markoviri, V. Matsuta, G. Mozhaeva, S. Shchebetenko reflect the main approaches to the development and modeling of the profile of educational interests of applicants and students, and most importantly, the possibility of their use for subsequent analysis $[6,7,8,9,10,15]$. For example, H. Schwartz in his publications showed the relationship of psychological characteristics of a person and his texts in social networks [15], and M. Kosinski noted the relationship of personal characteristics of an individual with the network resources visited [9].

Special attention in foreign studies is paid to integrated approaches to determining the psychographic portrait of the user, his psychological profiling, determining the content component of his actions on the basis of combining previously unconnected elements of the Internet technologies, analysis of its digital footprints. In this regard, it is of great interest to analyze the results of research on digital behavior of the individual, carried out in recent years.

\section{Results and Discussion}

Within the framework of the identified problem, our research justifies the development of a model of integrated professional orientation and professional self-determination of young people (school children and first-year students of universities, colleges, technical schools) in the educational territorial ecosystem created on the basis of professional interactions (the region, the country) for the digital economy of the future [6].The research substantiates the possibility of forming a trajectory of professional development of an applicant (individual training trajectory) based on processing large amounts of data, data obtained from the analysis of activity in social networks (based on the digital footprint). This allows us to define typical approaches and a list of sociological tools used for analyzing user data and their mathematical interpretation for organizing effective information impact (building a digital profile).

By digital footprint, we mean a unique set of user actions on the Internet, that is, information left as a result of browsing the web and saved as small pieces of data (cookies). The identification and analysis of digital traces of users allows us to identify their interests, preferences and inclinations, which are necessary in the future for targeted, "point" work 
with this audience, forming an expanded digital profile [4]. In this case, the digital profile will be represented as a set of digital records about individuals contained in information systems, network services, and social networks.

Digital data left by a person on the network can be used to model and predict individual psychological traits. Currently, the analyzed parameters of user profiles allow us to identify among them those who are open to searching for knowledge in a particular area, as well as potentially motivated to learn. This allows you to plan individual work and offer specific educational services to potential applicants, such as offering training courses related to mining, petrochemical technologies, and construction. As shown by the experience of Tomsk State University (2016-2018 years), the hypothesis that it is possible to identify the educational interests of a social network user through the analysis of thematic communities in which they are members has been confirmed (for the Humanities) [6,16]. Thus, such approaches, based on big data obtained from the analysis of digital user profiles, allow organizing a digital transformation work with young people. This makes it possible for the university to expand its geographical coverage in the search and selection of applicants future personnel for mining enterprises [3]. This can increase the relevance of the audience, organize personal communications, and organize targeted career guidance with potential applicants long before the start of the admission campaign to the university, which trains personnel for enterprises in the mineral resource cluster of the economy.

To use in practice the proposed methods for building a digital profile, it is necessary to develop an algorithm for selecting and preparing a set of data to determine the segmented target audience and their aggregation. In our case, this is the preparation of data that can identify applicants who are predisposed to study physics, chemistry, mathematics, have research experience, are interested in technology, exact sciences, participated in specialized olympiads or conferences, that is, correspond to the main areas of training at a technical university.

The next stage is to determine the map (matrix) of competencies for the digital economy of the future, select psychological and psychodiagnostic tools for identifying students' aptitudes into main groups (basic competencies of the digital economy, social management, modern engineering, natural sciences and biotechnologies, IT-competence, Humanities, science and art), and form typical patterns as the basis for the offered educational services [4]. This allows you not only to select potential students for the university, but also to recommend students the direction of further career development.

As a result, the concept of expanding a multi-level intellectual IT platform for a geographically distributed model of professional orientation and professional selfdetermination of young people in the form of a new educational ecosystem is formulated and justified. In the future, we will test the performance of components of a multi-level intellectual IT platform integrated with an organizational and pedagogical geographically distributed model of professional orientation and professional self-determination of young people in the region.

In accordance with the set goals, methods of interdisciplinary analysis and synthesis of philosophical, methodological, pedagogical, psychological, socio-economic literature, literature on computational mathematics, IT-technologies and network services are used in determining the methodological, theoretical and conceptual platform of the project, searching for evidence of the prospects of using the idea of integrating personal characteristics of subjects of professional self-determination obtained from social networks with the existing educational ecosystem; study of current experience in the field of professional orientation, professional self-determination of students in the conditions of digitalization of society, the emergence of new professions and the development of the economy of the future; extrapolation and design of systems and processes. When developing the concept of expanding a multi-level intellectual IT platform for a 
geographically distributed model of professional orientation and professional self determination of young people in the form of a new educational ecosystem, expert assessment, generalization, modeling, and design of systems and processes are used. The study of advanced foreign and domestic experience in the field of forming the trajectory of professional development of an applicant (individual learning trajectory) based on processing large amounts of data obtained from the analysis of activity in social networks (digital footprint) allowed us to move to multi-level structural and mathematical modeling to develop a matrix of competencies for the digital economy of the future, it provided the selection of psychological and psychodiagnostic tools for identifying the inclinations of potential students and the formation of typical patterns as the basis for the offered educational services $[11,14]$.

A special place among the research methods is occupied by linguistic data analysis (based on LIWC and NLTK) and psychodiagnostics methods-without them, it is impossible to work with user data of social networks of schoolchildren and first-year students to identify their educational needs and requirements for designing individual trajectories of personal and professional development within the mineral resource cluster.

At the final stage, the method of analyzing user data based on the morphology and syntax of text blocks on the accounts of network users, graphic objects and subscriptions allowed us to determine the personal characteristics of the owners, to justify the relationship between digital data from the user's profile in social networks and his real demographic, social and psychological characteristics and professional inclinations [16]. The use of correlation analysis, data interpretation, and taxonometry methods in the development of the algorithm for selecting and preparing a data set ensures the formation of a segmented target audience and their aggregation, taking into account the tasks being solved.

The planned activities allowed us to justify the possibility of using the data contained in a man's personal profiles that a person creates in social networks to analyze his or her intellectual and educational needs and then use them to meet their educational needs. This allowed us to bring the scientific basis to innovations introduced in the process of developing an individual trajectory of personal development. With regard to the admission campaign of the technical university, this allows you to pre-select candidates with aptitudes to study mining, construction, mechanical engineering, chemical and oil and gas technologies, which provides training for the mining industry, and in general for enterprises of the entire mineral resource cluster.

Based on the user's digital footprint, to solve the problem of individualization of the learning process, the principles of modeling the psychological, physiological and cognitive features of potential applicants (users of social networks) were clarified. The formed principles have expanded the methodological base at the intersection of pedagogy, psychology and sociology, and will form a single cluster for individualized career guidance and counseling. As a result, the justification of the sequence of work with data provides the formation of an individual trajectory of personal development (including the construction of a professional career) as a result of modeling educational interests [6]. The developed and tested methodology of integration and integrated use of standard tools of sociological research with machine learning methods based on linguistic analysis, cluster analysis, semantic analysis and taxonomy provides an increase in the effectiveness of career guidance mechanisms in the whole region.

Further research areas include the development and testing of algorithms for selecting and preparing a set of data to determine the segmented target audience and their aggregation, taking into account the tasks being solved. The obtained data will be used in the future to build a digital profile of the applicant (potential consumer of educational services). Analysis of digital footprints of potential applicants in social networks will allow 
you to predict the level of motivation to study in certain areas, taking into account intellectual development and creativity. Thus, the administrative and teaching staff of the university will have at their disposal tools that allow them to organize individual work with each student, identifying their difficulties at an early stage and using their preferences to develop creativity and initiative.

Refining the map (matrix) of competencies based on the selected aptitudes of students allows you to group students into groups, taking into account typical competence patterns as the basis for the offered educational services.

In the context of a broad digital transformation of the economy and public life, digital profiles of a person in network services and networks become a reflection of their personality. The development and use of publicly available digital data about users by KuzSTU and professional education organizations and the improvement of methods for collecting, cleaning and structuring them allows more productive and effective implementation of educational policies and mechanisms for providing educational services for quality and advanced training of the personnel for enterprises and organizations of the mineral resource cluster [12]. The transformation of existing systems and models of professional orientation and professional self-determination based on modern digital methods and big data processing can significantly increase its effectiveness.

\section{Conclusion}

The main result is a well-founded concept of expanding a multi-level intellectual IT platform for a geographically distributed model of professional orientation and professional self-determination of young people in the form of a new educational ecosystem. The concept is based on integration of existing components of the traditional system of career guidance and professional self-determination with an intelligent superstructure; integration of existing and new components and residents of various systems into an integrated ecosystem. The proposed concept will allow us to change radically the idea of professional self-determination as a temporary process at a certain stage of personal development, extend the activities for the formation and change of career for the entire professional activity of the individual, all this at the expense of an information resource of social networks and services that are not currently used for such purposes, add effective digital tools to a multi-level set of models of pedagogical support.

The implementation of these approaches in the activities of the university corresponds to the achievement of the strategic goals set by the KuzSTU and will strengthen its position as a university that trains highly qualified personnel for enterprises of the mineral resource cluster, increase the competitiveness of the educational organization in the market of educational services in the region and the country.

\section{References}

1. A. Khoreshok, A. Kuznetsov, A. Shalkov, E3S Web of Conferences, 41, 03004 (2018)

2. A. Kovalev, N. Rebrova, M. Zhidkova, E3S Web of Conferences, 41, 04026 (2018)

3. A. Krechetov, E3S Web of Conferences, 41, 0001 (2018)

4. Brown, T. Change by Desingn: How Desing Thinking Transforms Organizations and Inspires Innovation. Hasper Collins (2009)

5. A. Fagerstrøm, G. Ghinea. Journal of Higher Education Policy and Management. 1:35 (2013) 
6. D. Guest, J. Paauwe, P. Wright, HRM and Performance: Achievements and Challenges (Wiley, New York, 2013)

9. M. Kosinski, Machine learning, 3:95, 357-380 (2014)

10. D. Markovikj, ICWSM, 1, 271 (2013)

12. T. Panina, N. Kostyuk, S. Dochkin, E. Pahomova, Dilemas contemporaneous: Education, Politics and Values, 6:S, 4 (2019)

13. T. Panina, S. Dochkin, E3S Web of Conferences, 105, 04039 (2019)

14. R. Rutter S. Roper, F. Lettice, Journal of Business Research, 8:69, 3096-3104 (2016)

15. H. A. Schwartz, PloSone, 8:9, 73791 (2013)

16. A. Stepanenko, A. Feshchenko, Open and distance education, 4:68, 99 (2017)

17. V. Bobrikov, N. Ravichkin, V. Shshennikov, E3S Web of Conferences, 41, 04014 (2018) 